
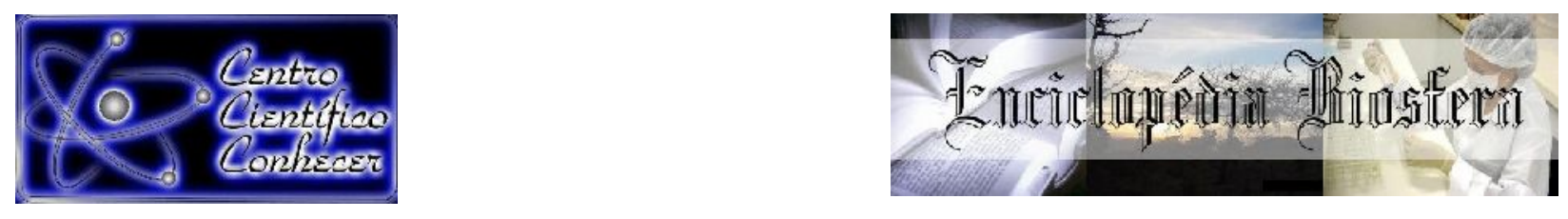

\title{
CARACTERIZAÇÃO BOTÂNICA E CADEIA PRODUTIVA DA ESPÉCIE Dipteryx alata Vogel
}

Claudiane Marques Ferreira ${ }^{1}$, Gabriela Hadler Gabriel ${ }^{2}$ Leandro Nepomuceno $^{3}$ Vanessa de Sousa Cruz ${ }^{4}$,Eugênio Gonçalves de Araújo ${ }^{5}$

1 Mestranda Programa de Pós-Graduação em Ciência Animal da Escola de Veterinária e Zootecnia da Universidade Federal de Goiás-Brasil

(marquesveterinaria@gmail.com)

2 Doutoranda do Programa de Pós-Graduação em Ciência Animal da Escola de

Veterinária e Zootecnia da Universidade Federal de Goiás Goiás-Brasil

3 Doutorando do Programa de Pós-Graduação em Ciência Animal da Escola de

Veterinária e Zootecnia da Universidade Federal de Goiás-Brasil

4 Pós doutoranda PNPD, Laboratório Multiusuário de Avaliação de Moléculas,

Células e Tecidos da Universidade Federal de Goiás-Brasil

5 Prof. Doutor do Setor de Patologia Veterinária da Universidade Federal de Goiás Goiás-Brasil

\section{Recebido em: 22/09/2018 - Aprovado em: 23/11/2018 - Publicado em: 03/12/2018} DOI: 10.18677/EnciBio_2018B18

\begin{abstract}
RESUMO
O Cerrado é o segundo maior bioma brasileiro e possui uma alta biodiversidade. Suas árvores frutíferas requerem baixo custo de manutenção por necessitar de poucos insumos químicos e podem ser utilizadas em áreas desmatadas ou degradadas. Porém, poucas espécies são conhecidas quanto à sua caracterização botânica e cadeia produtiva, sendo uma delas a Dipteryx alata Vogel. Esta espécie é uma leguminosa com alto potencial econômico e ampla gama de utilização, principalmente para a utilização de produto florestal não madeireiro. A exploração de $D$. alata é realizada de forma agroextrativista, sendo a casca e a polpa geralmente consumidas pela fauna, mas a polpa também pode ser utilizada para panificação. A amêndoa é comercializada em todo o Brasil, gerando uma forma de complementação de renda para produtores rurais. $O$ endocarpo lenhoso pode ser utilizado como fonte de carvão vegetal ou como artesanato para biojoias, mas na maioria das propriedades é descartado. Trata-se de uma espécie que pode contribuir para sistemas agroflorestais e recuperação de áreas degradadas, ao mesmo tempo fornecendo a polpa e amêndoa com altos teores de proteínas e minerais que podem contribuir para a panificação e substituição de alguns produtos consumidos atualmente com menores valores nutricionais, além de servir como fonte de renda complementar para produtores rurais. O objetivo desta revisão de literatura é descrever as características botânicas da espécie Dipteryx alata Vogel e sua cadeia produtiva como fator contribuinte para maior divulgação da espécie.
\end{abstract}

PALAVRAS-CHAVE: agroextrativismo, baru, cerrado. 


\title{
BOTANICAL CHARACTERIZATION AND PRODUCTION CHAIN OF SPECIES Dipteryx alata Vogel
}

\begin{abstract}
The Cerrado is the second largest Brazilian biome and has a high biodiversity. Its fruit trees require low maintenance costs because they require few chemical inputs and can be used in deforested or degraded areas. However, few species are known for their botanical characterization and productive chain, one being Dipteryx alata Vogel. This species is a legume with high economic potential and wide range of use, mainly for the use of non-timber forest product. The exploitation of $D$. alata is carried out in an agro-extractive way, the bark and the pulp are usually consumed by the fauna, but the pulp can also be used for baking. The almond is marketed throughout Brazil, generating a form of income supplementation for rural producers. The woody endocarp can be used as a source of charcoal or as crafts for biojoias, but in most properties it is discarded. It is a species that can contribute to agroforestry systems and recovery of degraded areas, at the same time supplying pulp and almond with high protein and mineral content, which can contribute to the baking and substitution of some products currently consumed with lower values nutritional benefits. In addition to serving as a source of complementary income for rural producers. The objective of this literature review is to evaluate the botanical characteristics of the species Dipteryx alata Vogel and its productive chain as a contributing factor for greater dissemination of the species.
\end{abstract}

KEYWORDS: baru, agroextractivism, cerrado.

\section{INTRODUÇÃO}

Na América do Sul, o Cerrado é o segundo maior bioma, depois da floresta Amazônica. Com clima tipicamente quente, semi-úmido e com invernos secos semelhantes às savanas, recebe o nome de Savana Brasileira (PINELI, et al., 2015). Possui sazonalidade variando entre invernos secos e verões chuvosos, mesmo com limitações de chuvas suas características são a heterogeneidade no habitat e nas diferentes condições de solo, além de alta diversidade de plantas (MENDONÇA et al., 2008).

As árvores frutíferas do cerrado estão adaptadas aos solos locais por demandarem baixos custos de implantação e manutenção, necessitando de poucos insumos químicos e passíveis de utilização em áreas desmatadas ou degradadas, enriquecimento da flora, parques e jardins, além de áreas de proteção ambiental e acidentadas para controle de erosão (VIEIRA et al., 2010). Mesmo com alta biodiversidade, poucas espécies são conhecidas, sendo uma delas a Dipteryx alata Vogel (NUNES et al., 2016).

No estado de Goiás, esta espécie é popularmente conhecida como baru e em outras regiões como coco-feijão, barujo, cumaru e cumbaru (MARCELINO et al., 2018). Sua amêndoa é rica em proteínas, minerais essenciais, fibras e lipídeos e possui boa aceitação por ter sabor agradável (FERRAZ et al., 2014; SOUZA; SILVA, 2015). D alata deixou de ser uma planta no meio da pastagem com frutos deixados para alimentação do gado para gerar produtos comercializados em mercados locais e em centros urbanos (SAWYER, 2012).

Considerada uma fonte de comércio viável para produtores rurais, a cadeia produtiva dessa espécie promove o desenvolvimento local (PINELI et al., 2015; SANTOS et al., 2016) e sustenta a diversidade, pois os recursos naturais servem de estímulo para esses fatores e permitem que a comunidade reative a economia e 
inicie o progresso de qualidade de vida sócio-cultural e ambiental (CARNEIRO et al., 2014).

Porém, segundo Sano et al. (2016), existem problemas que atrapalham um maior aproveitamento da espécie como o desconhecimento sobre o manejo, mercado, agregação de valor, além da flutuação da produção sazonal e dos preços. Diante disso, objetivou-se com essa revisão de literatura avaliar as características botânicas da espécie Dipteryx alata Vogel e sua cadeia produtiva como fator contribuinte para maior divulgação da espécie.

\section{CARACTERÍSTICAS BOTÂNICAS}

$D$. alata é uma leguminosa arbórea pertencente ao reino Plantae, subreino Tracheobionta, subdivisão Spermatophyta, divisão Magnoliophyta (Angiospermas), classe Magnoliopsida (dicotiledôneas), subclasse Rosidae, ordem Fabales, família Fabaceae, subfamília Faboideae, tribo Dipterygeae, gênero Dipteryx, espécie Dipteryx alata Vogel.

É uma espécie nativa do cerrado (PINELI et al., 2015), porém não é endêmica no Brasil (SANO et al., 2016). Possui distribuição irregular de indivíduos, mas geralmente com formações de grandes aglomerados (NABOUT et al., 2010) em locais de solos mais férteis (RIBEIRO et al., 2000; CORREA et al., 2008), bem drenados e de textura arenoargilosa, ocorrendo em menor quantidade em regiões savânicas e mais em formações florestais (SANO et al., 2016) (Figura 1). Fora do bioma cerrado, ela abrange regiões do Paraguai, Bolívia (ARAKAKI et al., 2009) e Peru (BRAKO; ZARUCCHI, 1993).

A reprodução da espécie ocorre por alogamia, necessitando de agentes polinizadores para que ocorra o fluxo de pólen entre as plantas para a frutificação (OLIVEIRA ; SIGRIST, 2008). Este fator é confirmado também pela presença de película estigmática que impede a autopolinização natural. Porém, estudos de análise molecular (SSR) confirmaram sistema reprodutivo misto, com autofecundação e cruzamento entre parentes e dispersão a longa distância do pólen (TARAZI et al., 2010). Em um estudo realizado por Oliveira e Sigrist (2008), os autores observaram uma maior polinização realizada por abelhas, sendo a Xilocopa suspecta considerada o agente efetivo por promover fluxo polínico entre plantas, enquanto Apis mellfera permanecem na mesma copa. Assim, a conservação de agentes polinizadores pode ser fator vital para a manutenção da espécie (SANO et al., 2016).

A produção de mudas geralmente é originária da semente de frutos maduros, sabendo que há pouca variabilidade nas propriedades das sementes por indivíduo. A germinação da semente apresenta-se com taxas acima de $90 \%$ e ocorre entre 40 a 60 dias dentro do fruto e 13 a 20 dias fora do fruto, devido à presença do rígido endocarpo. A profundidade da semeadura é recomendada de 1 a $3 \mathrm{~cm}$ em ambiente ensolarado (RIBEIRO et al., 2000). O espaçamento varia de acordo com 0 objetivo do plantio e, para fins florestais, sugere-se espaçamento de $3 \times 1,5 \mathrm{~m}$ entre indivíduos (SIQUEIRA et al., 1993). Para produção de frutos foram utilizados $2 \times 2 \mathrm{~m}$ e 3 x 3m (SANO et al., 2016). 


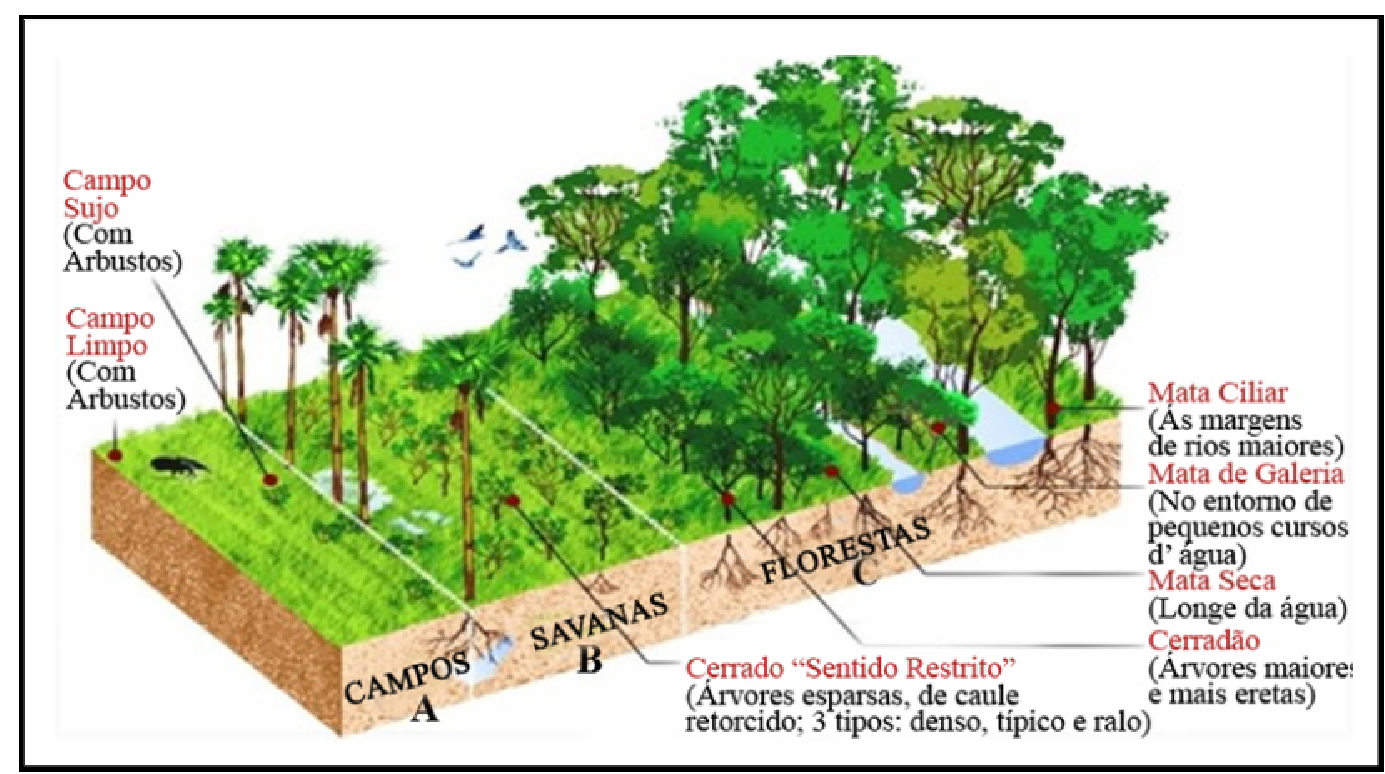

FIGURA 1 - Fitofisionomia do bioma cerrado. A) Os campos e suas divisões entre campo sujo com arbusto e campo limpo sem arbustos. B) As savanas, considerada o cerrado em seu sentido restrito, com árvores esparsas, de caule retorcido, dividido em três tipos: denso, típico e raio. C) As florestas divididas em: mata ciliar, definida como margens de rios maiores; mata de galeria, situadas no entorno de pequenos cursos d'água; mata seca, longe da água; e cerradão, de árvores maiores e mais eretas.

Fonte: Complexo vegetacional do Bioma Cerrado. Biomas brasileiros - Cerrado. Acesso em 5 de junho de 2017. Adaptado: https://matoecia.. logspot.com/searchq=cerrado.

Devido ao seu uso múltiplo, a taxa de germinação de sementes e o estabelecimento de mudas, a $D$. alata é uma espécie considerada muito promissora para pastagens cultivadas e em silviculturas (OLIVEIRA; SIGRIST, 2008; SANTOS et al., 2012), com taxas de sobrevivência superiores a $80 \%$ (NIERI et al., 2018). No cultivo comercial, podem ser produzidos em cada hectare $850 \mathrm{~kg}$ de amêndoas e 19 toneladas de polpa (RIBEIRO et al., 2000).

A primeira frutificação ocorre geralmente aos seis anos, mas isso depende do índice pluviométrico e da qualidade do solo (Sano et al., 2016). A altura da D. alata é entre 5 e $10 \mathrm{~m}$, mas pode alcançar até $25 \mathrm{~m}$, com caule ereto de até $0,7 \mathrm{~m}$ de diâmetro. Sua copa possui apresentação densa e arredondada com cerca de 6 a 11 metros de diâmetro (SANO et al., 2016) (Figura 2). O tronco é liso ou com formação de placas irregulares e descamantes. A coloração varia do creme ao cinza claro (ALMEIDA et al., 1998).

As folhas são compostas, pinadas, alternas, exceto as primordiais, são pecioladas, sem estípulas e com raque alada. Os folíolos, em número de 7 a 12 , possuem alternos ou subpostos, subsésseis ou com pecíolo de até de $2 \mathrm{~mm}$ comprimento. O limbo raramente apresenta-se suborbicular, sendo mais em formato oblongo com 4 a $13 \mathrm{~cm}$ de comprimento e 2 a $6,5 \mathrm{~cm}$ de largura. A apresentação é cartáceo, com ápice obtuso adrupto-acuminado, pontuações translúcidas diminutas, base arredondada desigual, truncada ou subcordada, e na face ventral nervura mediana plana. As nervuras secundárias são numerosas, ascendentes, salientes nas duas faces de maneira igualitária (ALMEIDA et al., 1998). 


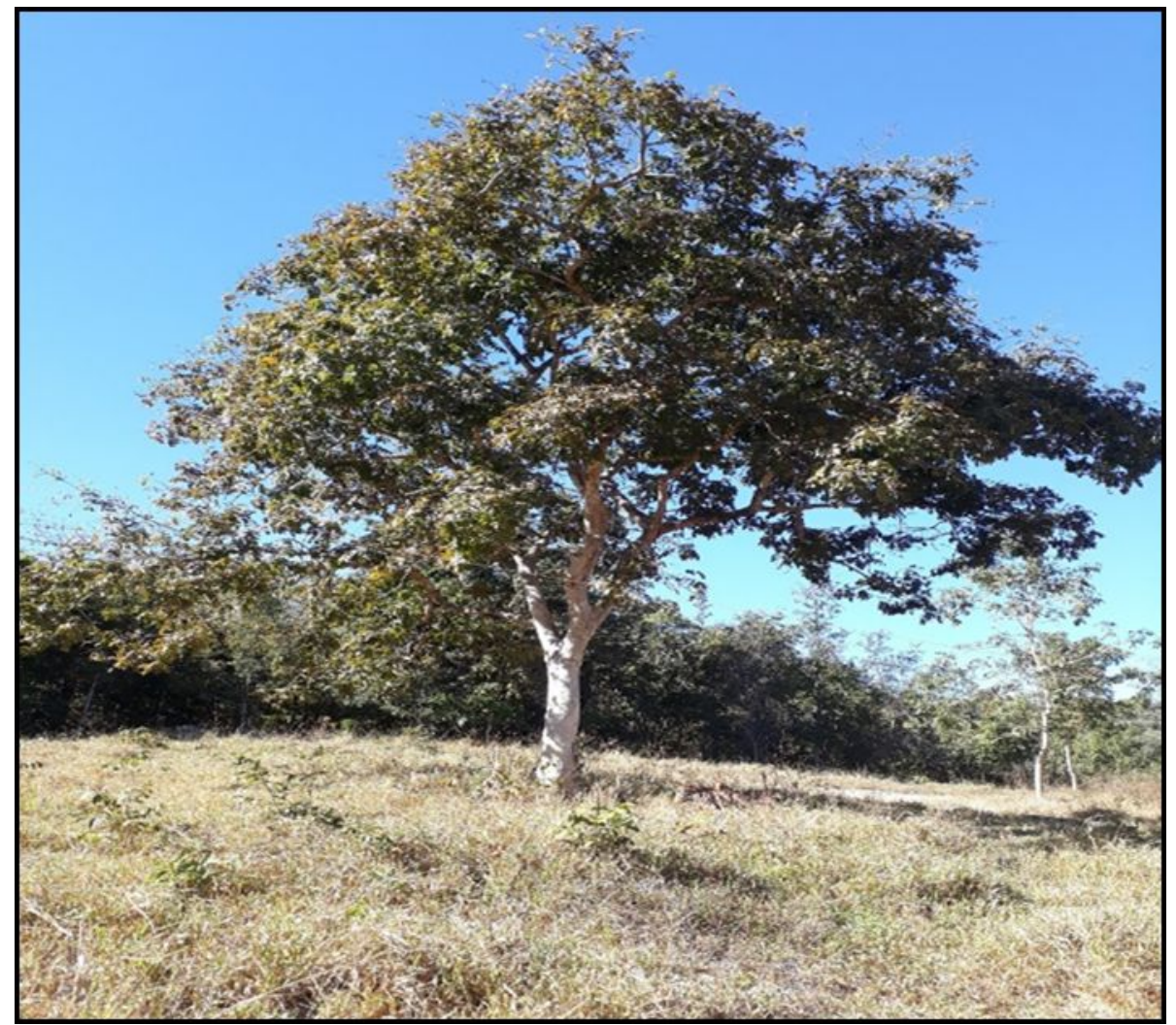

FIGURA 2 - Espécie Dipteryx alata Vogel em Pirenópolis Goiás. Árvore com altura entre 5 a $10 \mathrm{~m}$ de altura, podendo alcançar $25 \mathrm{~m}$, apresentando caule de $0,7 \mathrm{~m}$ de diâmetro e com copa densa e arredondada.

Fonte: Arquivo pessoal (2017).

A inflorescência é uma panícula terminal, com flores dispostas em vários eixos, com $8 \mathrm{~mm}$ de comprimento, localizada nas axilas das folhas superiores contendo 200 a 1000 flores com coloração branco-rosada, brácteas valvares com pontuação translúcidas, caducas antes da antese (ALMEIDA et al., 1998).

As flores são hermafroditas, curto-pediceladas, com $0,8 \mathrm{~cm}$ de comprimento (Figura 3). Possuem cálice petaloide, 3 dentes menores e 2 maiores, alvo, oblongo ciliado simulando um vexilo com manchas carmim. Anteras rimosas e ovais. Com corola papilionácea alva, vexilo suborbicular, emarginado. Alas e carenas livres, longo unguiculadas, elípticas com 10 estames subiguais, monoadelfos. $\mathrm{O}$ ovário possui um só óvulo parietal inserido próximo ao ápice, é unilocular, súpero, breveestipitado e linear (ALMEIDA et al., 1998). 


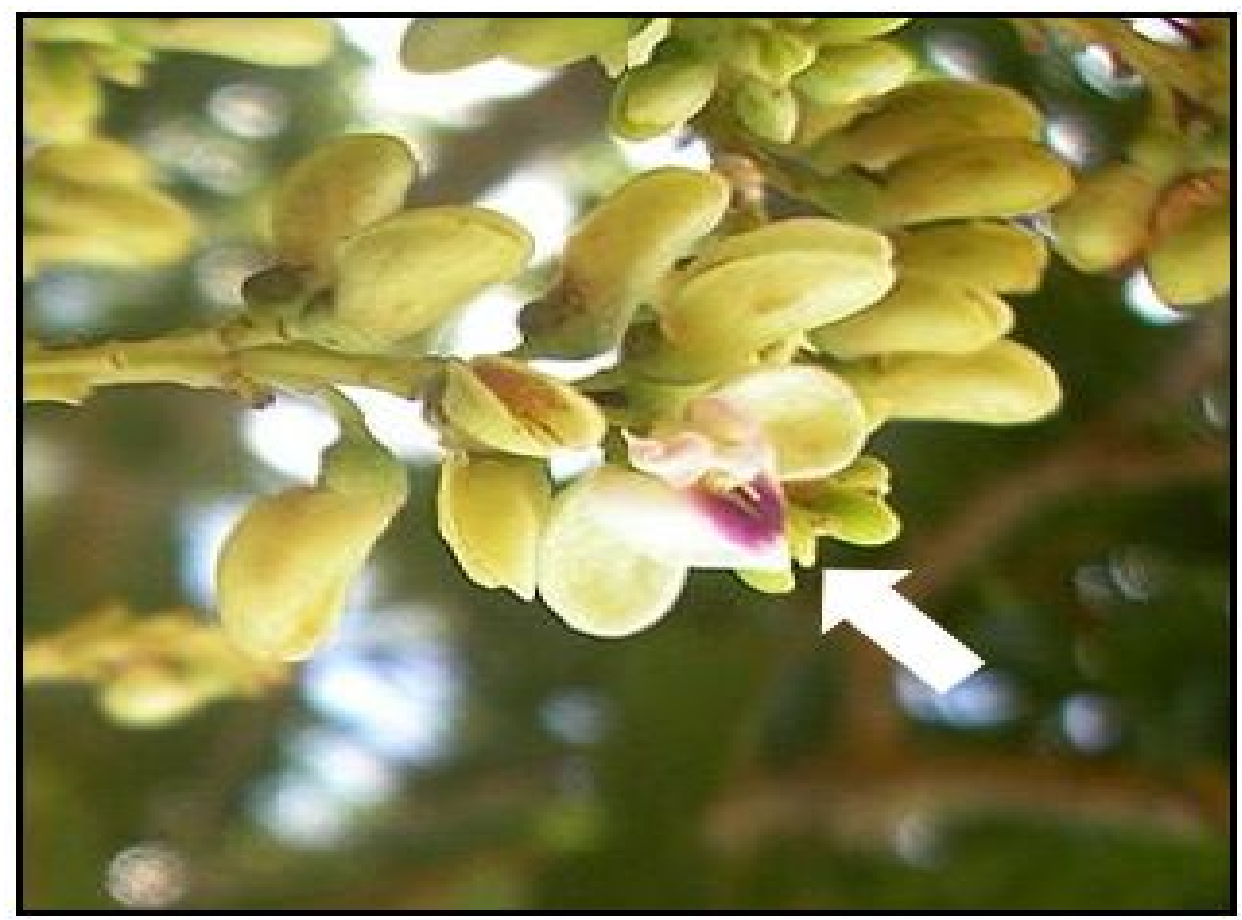

FIGURA 3 - Inflorescência de Dipteryx alata Vogel. Consiste em uma panícula terminal com flores (setas) dispostas em vários eixos e coloração branco-rosadas.

Fonte: Flores do Baru. Foto de Denis A. C. Conrado. Acesso em 04 de novembro de 2018. Retirado e adaptado do site: https://www.jardineiro.net/plantas/baru-dipteryx-alata.html

A ocorrência da floração é de novembro a fevereiro (RIBEIRO et al., 2000) e a formação dos frutos ocorre de janeiro a outubro com maturação entre março e agosto (SANO et al., 2016). Cada árvore pode produzir de 2000 a 6000 frutos por planta, o que rende, em média, $150 \mathrm{~kg}$ de frutos por safra (SANO et al., 2016). A safra é intermitente em relação à produção de frutos anuais, sendo produtiva a cada dois anos (OLIVEIRA; SIGRIST, 2008).

Os frutos maduros no chão são encontrados embaixo dos indivíduos arbóreos (BAILÃO et al., 2015), o que ocorre por gravidade (dispersão barocórica) ou podem ser levados para locais distantes por serem transportados pela fauna (dispersão zoocórica) (SANO et al., 2016). Os bovinos são um dos agentes dispersores, se alimentando da casca e polpa e eliminando os caroços pela pastagem. O morcego também é um, que ao transportar o fruto pode deixar cair pelo caminho ou em seu local de pouso. A alimentação da polpa pela fauna favorece o surgimento de novas plântulas, pois os caroços germinam melhor sem a polpa (SANO et al., 2016).

Os frutos são classificados como legumes do tipo drupa (BAILÃO et al., 2015) indeiscente, monospérmico, com formatos não definidos, mas geralmente ovoides. Apresentam-se fibrosos, opacos, com cor variando entre bege-escuro a marrom-avermelhado. Sua superfície é irregular com algumas depressões e textura lisa. Seu ápice é arredondado com bordo inteiro e base estreita e um dos lados levemente achatado com uma linha semelhante a uma linha de sutura (FERREIRA et al., 1998) (Figura 4). 


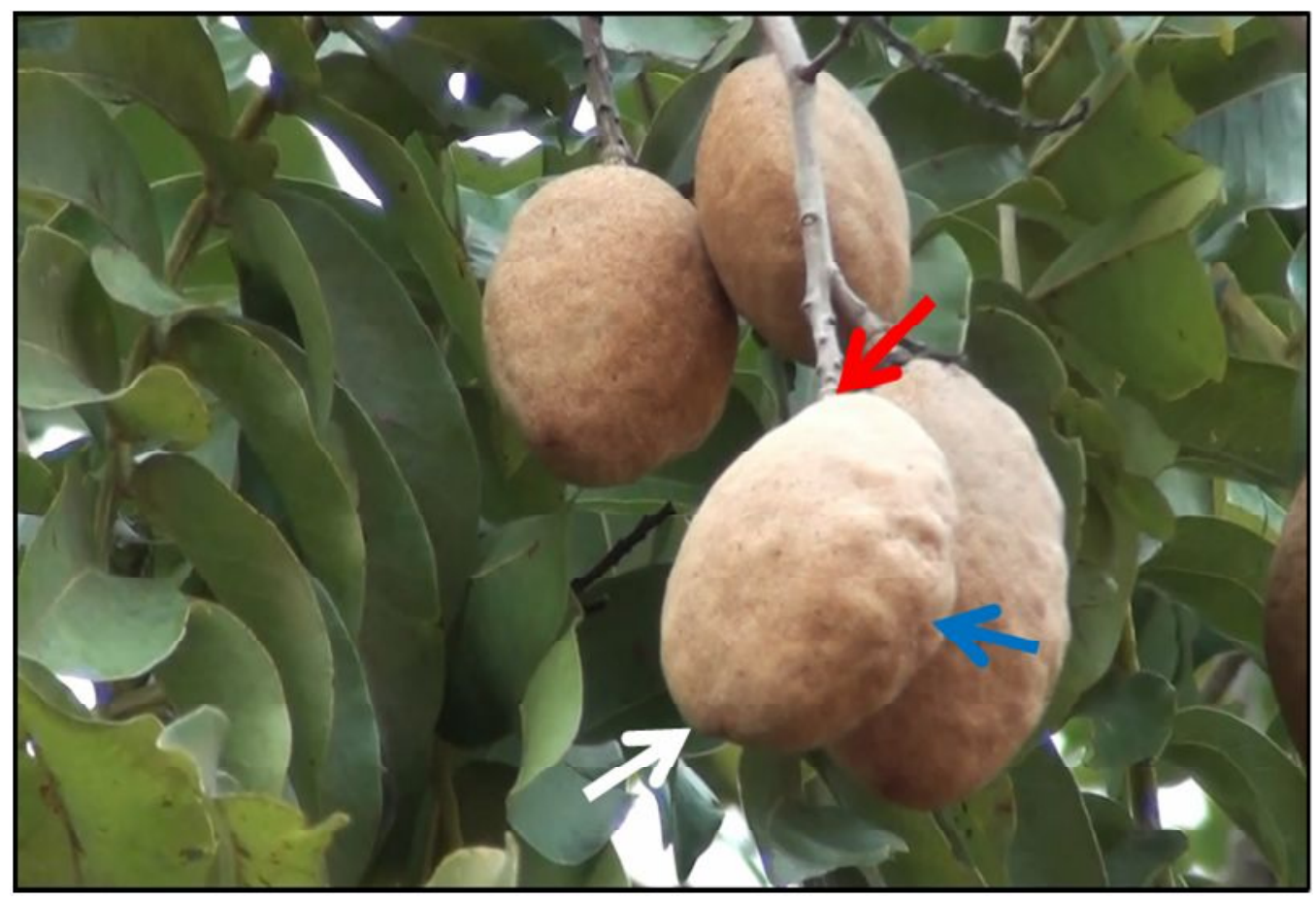

FIGURA 4 - Fruto do Dipteryx alata Vogel. Fibrosos de cor entre begeescuro a marrom- avermelhado, opaco. Com superfície irregular de textura lisa ou com depressões. Ápice arredondado (seta branca), base estreita (seta vermelha) e bordo inteiro (seta azul), com um dos lados levemente achatado.

Fonte: Adaptado de https://www.youtube.com

Os tamanhos do fruto variam entre 3 a $7 \mathrm{~cm}$ de diâmetro com peso entre 26 e $40 \mathrm{~g}$ (SANO et al., 2016). Estas diferenças de tamanho e peso entre os indivíduos estão associadas às características genéticas de cada indivíduo (CANUTO et al., 2015), condições de temperatura e indicies de pluviosidade, ou seja, observa-se variação dos frutos entre plantas e não entre frutos dentro de cada planta (CORREA et al., 2000).

O fruto apresenta três camadas: epicarpo (casca) fino de cor marrom, quebradiço e macio; o mesocarpo (polpa) possui consistência macia, farináceo, espesso (Figura 5) (FERREIRA et al., 1998), com sabor adocicado e adstringente, ainda pouco utilizado na alimentação humana (RIBEIRO et al., 2000) e o endocarpo lenhoso, de difícil rompimento (FETZER et al., 2018) pela sua resistência (SOARES, 2015), nas cores amarelo esverdeado ou marrom com uma camada esponjosa na parte interna (FERREIRA et al., 1998). 


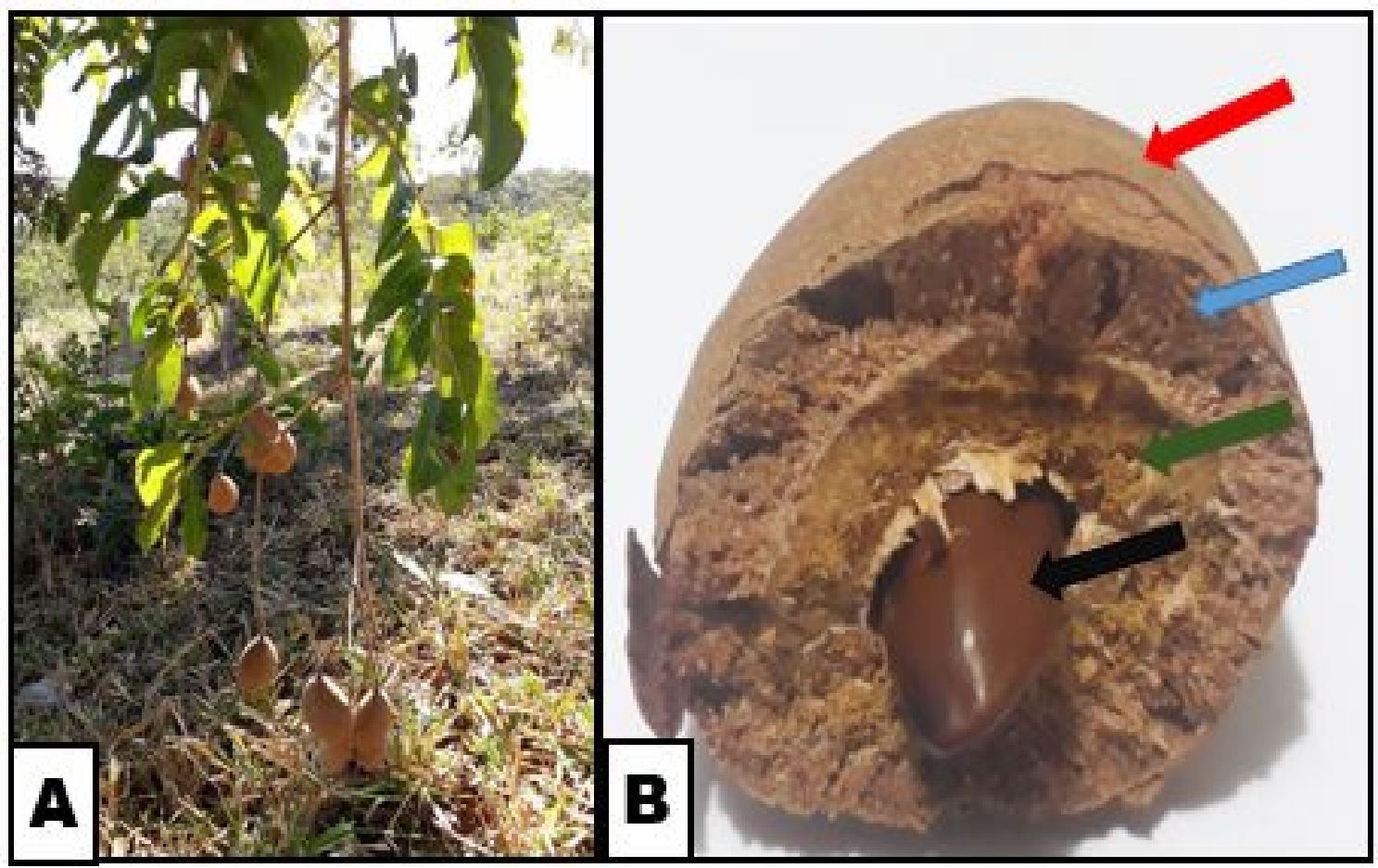

FIGURA 5 - Espécie Dipteryx alata Vogel, baru. A - Espécie Dipteryx alata Vogel. B - Fruto da espécie, epicarpo (casca) seta vermelha; pericarpo (polpa) seta azul; endocarpo seta verde; amêndoa seta preta.

Fonte: Arquivo pessoal (2017).

A semente é única, com peso médio de $1,17 \mathrm{~g}$ (CORREA et al., 2008) com cerca de $2,5 \mathrm{~cm}$ de comprimento (ALMEIDA, 1998) com coloração de branco a creme. Seu formato varia de largo elíptico a ovalado (FERREIRA et al., 1998; CORREA et al., 2008) e possui uma película envolta de cor marrom escura. Se o rendimento do fruto for considerado somente pela amêndoa, fica em torno de $5 \%$. Todavia, ao se utilizar também a polpa, o rendimento aumenta para $50 \%$. Ainda assim, a amêndoa é a peça central da cadeia produtiva dessa espécie (RIBEIRO et al., 2000).

\section{CADEIA PRODUTIVA}

Considerada uma espécie de grande potencial econômico, a $D$. alata é uma das mais promissoras para cultivo devido à sua ampla gama de utilização (MARCELINO et al., 2018; NIERI et al., 2018). Dentre elas, incluem-se os usos industriais, na tecnologia de alimentos (FERNANDES et al., 2015), paisagístico, recuperação de áreas degradadas, sistemas agroflorestais e na alimentação humana e animal (ALBUQUERQUE et al., 2013).

Há um grande interesse em sua madeira devido à densidade $\left(1,10 \mathrm{~g} / \mathrm{cm}^{3}\right)$, nível de compactação, elevada resistência ao apodrecimento e alta durabilidade. No Peru, em 2008, quase a metade das exportações de madeira foram de espécies de Dipteryx sendo $80 \%$ enviado para a China para produção de pisos (PUTZEL et al., 2010).

A espécie possui potencial econômico como um produto florestal não madeireiro, e em Goiás é protegida do corte pela portaria número 918/2002 da 
Agência Goiana do Meio Ambiente (SANTOS et al., 2012). No desmatamento do cerrado para abertura de pastagens, as árvores de $D$. alata geralmente são preservadas, pois além de servir como abrigo para o gado, apresentam polpa carnosa, constituindo uma das poucas espécies com produção durante a estação seca, complementando a alimentação da fauna quando há pouca disponibilidade de alimentos, inclusive forragem para bovinos (SANO et al., 2016) (Figura 6). Por esse motivo é considerada uma espécie chave, alimentando morcegos, macacos, roedores (cutia e paca), insetos (coleópteros), aves (tucano) e os bovinos (NABOUT et al., 2010).

A exploração é por meio do agroextrativismo (CARNEIRO et al., 2014). Um dos locais onde ocorre a exploração da amêndoa de $\mathrm{D}$. alata é Pirenópolis, em Goiás, onde a espécie era utilizada pelos agricultores como fonte de madeira e a polpa do fruto para consumo da fauna, principalmente para o gado criado de forma extrativista. Há relatos dos agricultores de que a amêndoa servia de alimentação para crianças durante a seca enquanto brincavam pela mata. A castanha torrada passou a ser utilizada como petisco entre os moradores da região rural de Pirenópolis entre os anos de 1996 e 1997 (CARNEIRO et al., 2014).

Como alimentação natural e saudável, a castanha torrada passou a ser vendida para os turistas de Pirenópolis com auxílio do projeto de Desenvolvimento Sustentável na Exploração do $D$. alata, da Fundação Pró-Natureza (FUNATURA) e Centro Educacional SESC Cidadania (CENESC). Além disso, o apoio de parcerias não-governamentais e governamentais ao Projeto $D$. alata uniu agricultores familiares, ambientalistas, extrativistas e pesquisadores da Universidade Federal de Goiás com o intuito de uma unidade de processamento integral (CARNEIRO et al., 2014). Além disso, houve formação de cooperativas com o objetivo de melhorar o aproveitamento dos frutos e conservação da espécie (BAILÃO et al., 2015).

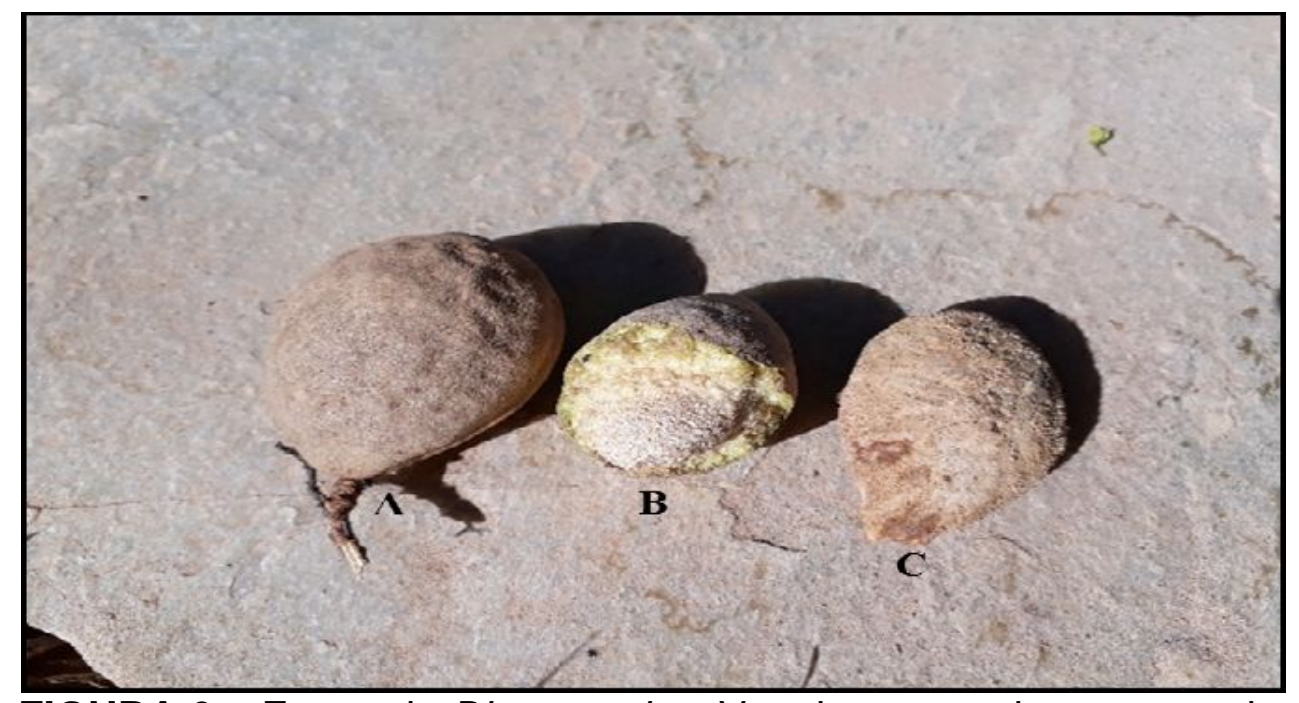

FIGURA 6 - Frutos do Dipteryx alata Vogel encontrados no cerrado.

A) Fruto intacto demonstrando casca e polpa. B) Fruto com a polpa parcialmente retirada pela fauna local. C)

Fruto com a polpa totalmente retirada pela fauna local.

Fonte: Arquivo pessoal (2017).

Os resultados geraram a venda das castanhas como uma forma de complementação de renda para os produtores rurais nos períodos de entressafra do estado de Goiás (ARAUJO et al., 2013) e se disseminou para outros estados. A 
amêndoa e a polpa podem ser encontradas em mercados regionais de produtos alimentícios em todo o país. A aceitação pelos consumidores se deve ao fato dos frutos do cerrado possuírem aromas, texturas e odores diferentes das demais frutas e preço competitivo (ARAKAKI et al., 2009).

Não há uma regularidade na comercialização, geralmente ocorrendo somente no período de safra e em poucos meses após, pela dificuldade de armazenagem por parte de alguns extrativistas (SANO et al., 2016). A rentabilidade do extrativista pode ser maior por meio de associações ou cooperativas, pois essas organizações podem orientar a cadeia produtiva até a comercialização. A amêndoa é considerada uma iguaria cada vez mais apreciada, por ser um produto sem insumos químicos e com manejo natural (NOGUEIRA, 2005). Entretanto, podem existir problemas na qualidade do produto comercializado por não haver uma padronização na torrefação com fornos sem controle de tempo e temperatura, sendo realizado de maneira artesanal e dificultando a entrada desse produto no mercado (NOGUEIRA, 2005).

A coleta do fruto demanda tempo, pois o mesmo é coletado maduro do chão e sua dispersão é irregular, pois a fauna, ao consumir a polpa, espalha o endocarpo com a amêndoa para outros locais. Outros extrativistas estendem lonas abaixo da árvore para amparar os frutos ainda imaturos que são armazenados até sua maturação (SANO et al., 2016). Independente da maneira de coleta, alguns extrativistas não coletam todos os frutos, deixando alguns para a alimentação da fauna e dispersão de suas sementes (CARNEIRO et al., 2014).

Para extrair a amêndoa, o endocarpo deve ser cortado transversalmente ou por pressão mecânica. Uma foice adaptada a um pedaço de vigota com uma superfície convexa do tamanho médio dos frutos da $D$. alata é utilizada por muitos extrativistas (Figura 7), pois a quebra por ferramentas como o martelo pode danificar a semente (SANTOS et al., 2012). A ideia do cortador de foice surgiu em 1998 e ele foi desenvolvido em Pirenópolis por artesãos e distribuídos para outras comunidades (RIBEIRO et al., 2000).

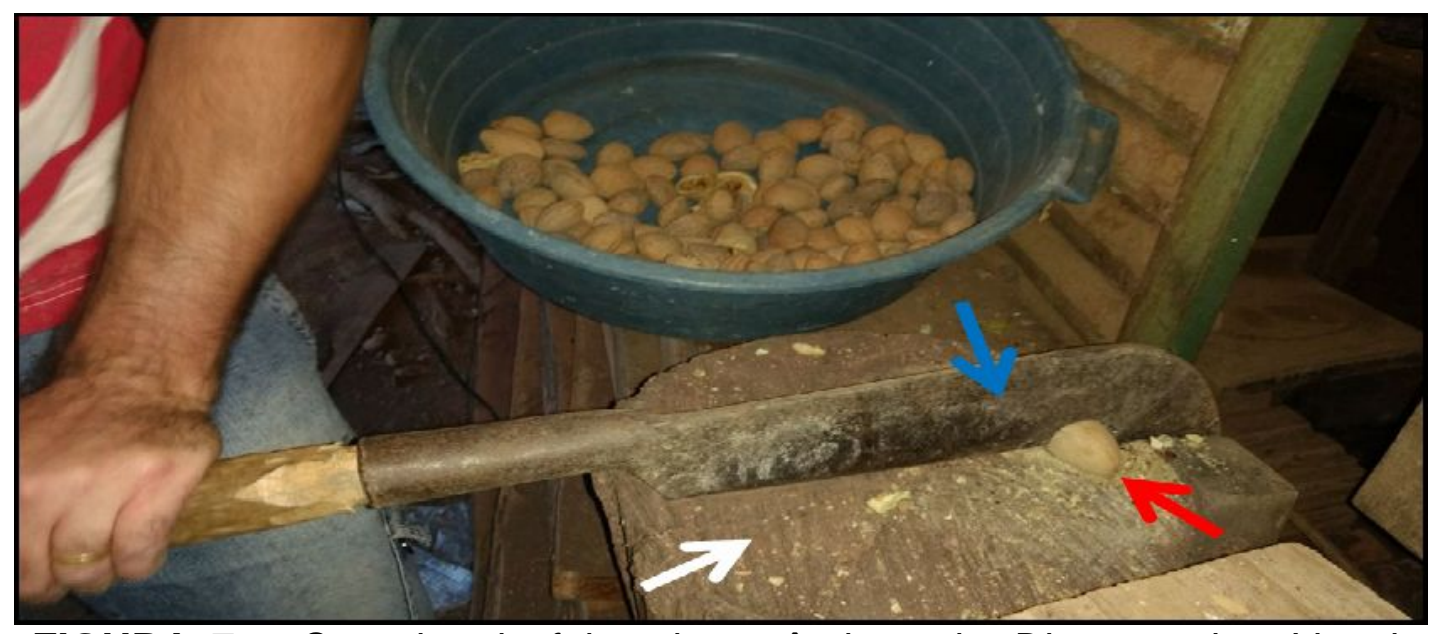

FIGURA 7 - Cortador de foice de amêndoas do Dipteryx alata Vogel. Mecanismo desenvolvido por artesãos de Pirenópolis em 1988 para quebra do endocarpo lenhoso sem danificar a amêndoa. Um pedaço de vigota (seta branca) com uma superfície convexa (seta vermelha) para inserção dos frutos do Dipteryx alata Vogel e uma foice adaptada (seta azul). Fonte: Arquivo pessoal (2017). 
O endocarpo é descartado nas propriedades coletoras do fruto (Figura 8 A), mas pode ser aproveitado como fonte de energia de forma sustentável, utilizado como carvão ou por meio do artesanato para fabricação de biojoias (Figura 8 B) (VALE et al., 2013).

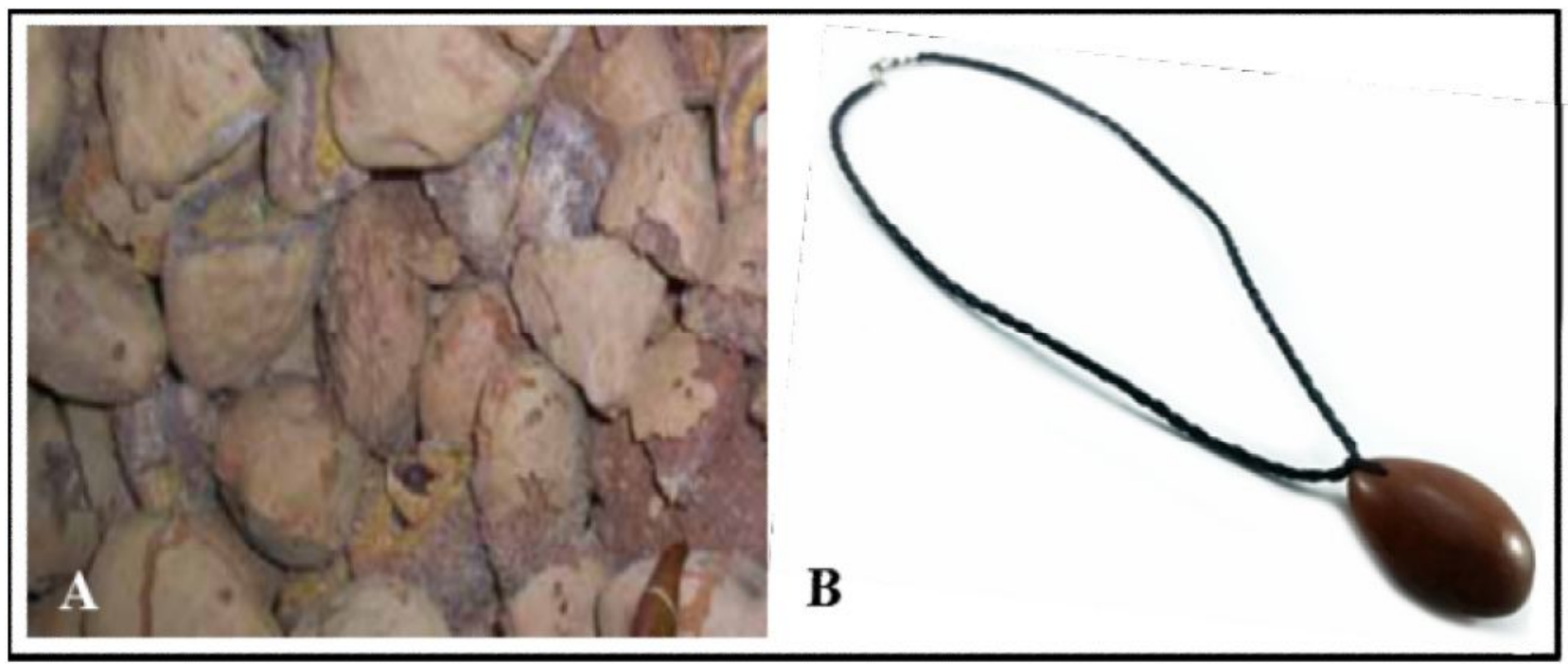

FIGURA 8 - Dipteryx alata Vogel. A) Endocarpo lenhoso - o fruto descartado após a quebra para a retirada da amêndoa. B) Colar produzido com o endocarpo. Fonte: Carrazza; D’Ávila, 2010. https://www.elo7.com.br/colarbaru/dp/4DAE

A polpa e amêndoa são as partes comestíveis (SILVA et al., 2015, RESENDE et al., 2018). A polpa apresenta sabor doce e cor amarelo (NUNES et al., 2016) a qual (Figura 9) pode ser feita farinha de panificação e fabricação de licor (SANO et al., 2016). Diferentes tipos de farinhas baseadas em frutos regionais são produzidas para agregar valor aos produtos do mercado de panificação e o intuito seria valorizar e incentivar o consumo dos frutos do Cerrado, melhorando os atributos nutricionais. A aceitação pelos consumidores da produção de panificação com a polpa da $D$. alata já foi testada, inclusive, em panetone, com resultados positivos (ANDRADE et al., 2016).

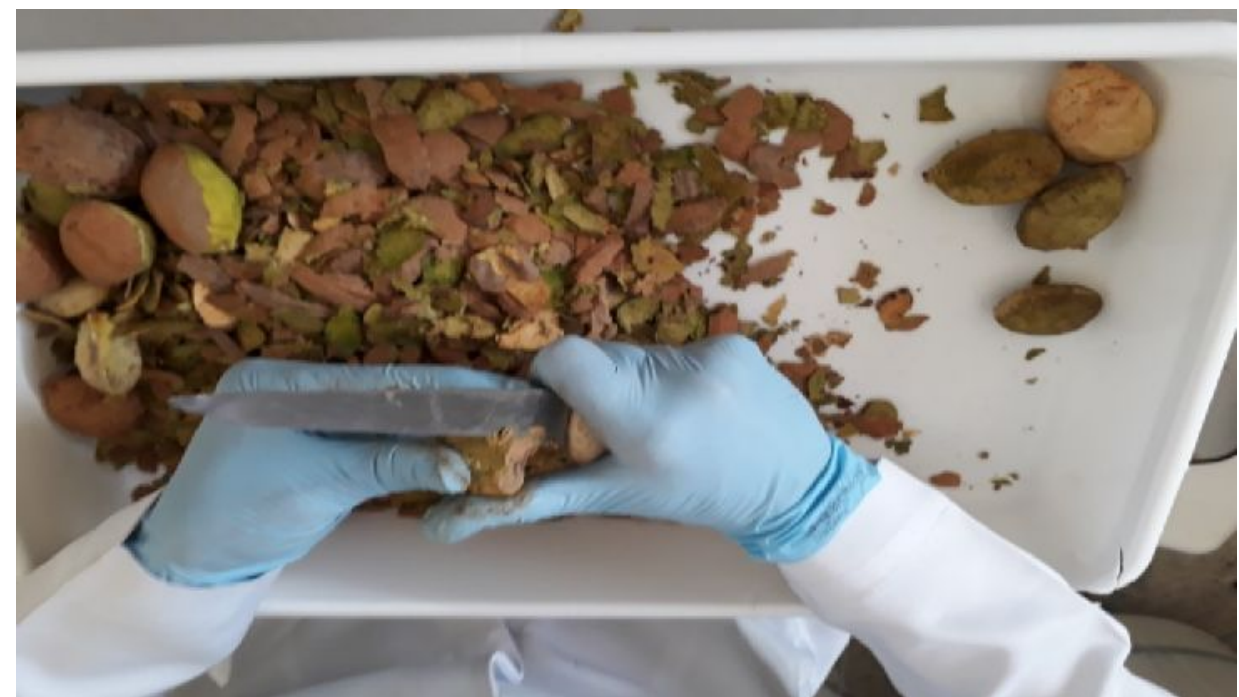

FIGURA 9 - Processamento do fruto de Dipteryx alata Vogel. Fonte: Arquivo pessoal (2017). 
A polpa é fonte importante de teor de açúcares totais e fibra alimentar. Seu valor calórico é de aproximadamente $300 \mathrm{kcal} / 100 \mathrm{~g}$, composto com cerca de $63 \%$ de carboidrato, sendo em sua maior parte amido, açúcares e fibras insolúveis. Com a casca os carboidratos representam $65 \%$, lipídios $3,3 \%$, fibras $4,39 \%$ e proteínas 4,45\% (SANO et al., 2016).

A amêndoa da $D$. alata crua não é recomendada para alimentação por possuir fatores antinutricionais em sua constituição como tanino, inibidor de tripsina e ácido fítico que impedem a absorção de outros nutrientes, além de dificultar a digestão de proteínas (SOUSA; SILVA, 2015). Todavia, o calor pode inativar o inibidor da tripsina (SANO et al., 2016). A torrefação é o método utilizado por ser capaz de melhorar a digestibilidade das proteínas e inativar os antinutrientes, formando compostos aromáticos causando escurecimento e evaporação de água (LEMOS et al., 2012) (Figura 10).

A amêndoa crua possui em média $476 \mathrm{kcal} / 100 \mathrm{~g}, 38,2 \mathrm{~g} / 100 \mathrm{~g}$ de lipídios, $23,9 \mathrm{~g} / 100 \mathrm{~g}$ de proteínas, $15,8 \mathrm{~g} / 100 \mathrm{~g}$ de carboidratos e $13,4 \mathrm{~g} / 100 \mathrm{~g}$ de fibras (PINELI et al., 2015). O teor de proteínas de sua amêndoa é superior à da amêndoa do pequi do amendoim e da amêndoa do caju, isso sempre após torrefação (SOUSA et al., 2011). Os valores de conteúdo mineral são considerados altos, $140 \mathrm{mg} / 100 \mathrm{~g}$ de cálcio, $827 \mathrm{mg} / 100 \mathrm{~g}$ potássio e $358 \mathrm{mg} / 100 \mathrm{~g}$ fósforo (LEMOS et al., 2012) Os valores são variáveis entre os indivíduos arbóreos e isso se deve às práticas agrícolas, clima solo e características inerentes de cada um (FERNANDES et al., 2010). Dos ácidos graxos avaliados na amêndoa de baru, o ácido oleico representou $48 \%$ da sua composição (SANTOS et al., 2016). A alta proporção de ácidos graxos saturados e insaturados do óleo da amêndoa do baru proporcionam um consumo apropriado para os humanos (FERNANDES et al., 2015; SANTOS et al., 2016; SIQUEIRA et al, 2016). Em outro estudo, o ácido oleico representou variação de $50,52 \%$ a $53,35 \%$ e $24,59 \%$ de ácido linoleico (FETZER et al., 2018).

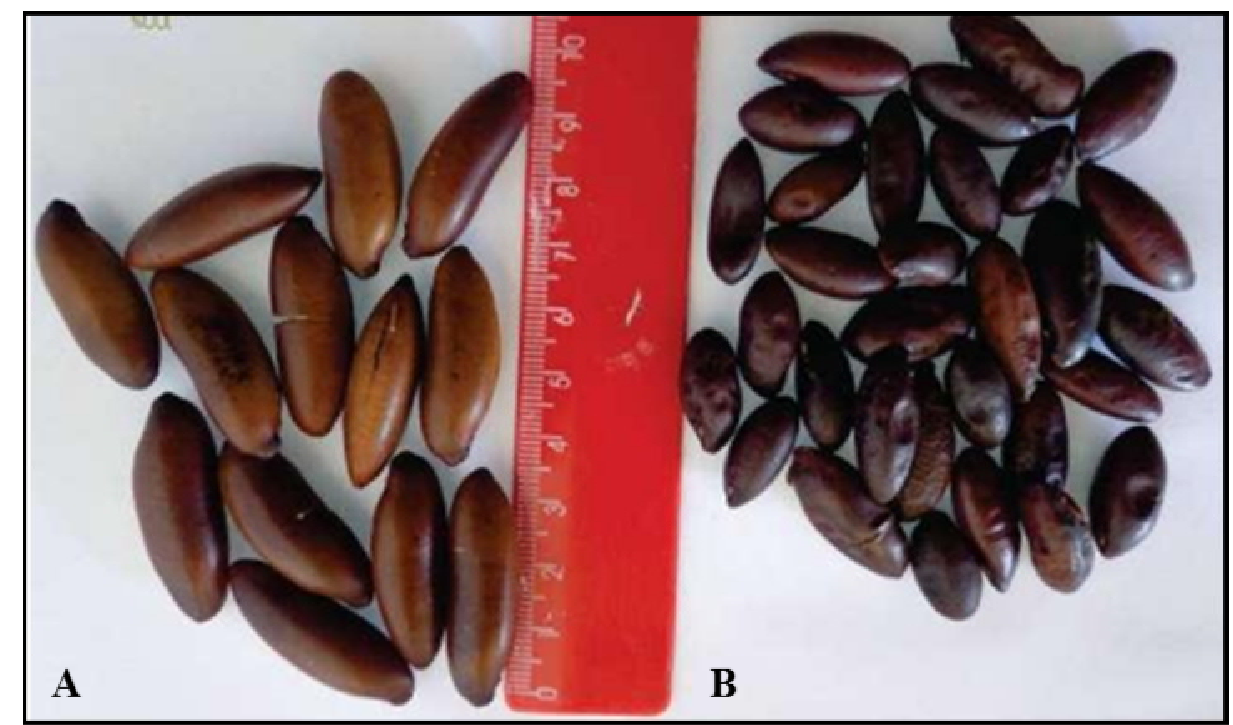

FIGURA 10 - Dipteryx alata Vogel. A) Amêndoa in natura. B) Amêndoa torrada por torrefação.

Fonte: http://www.mfrural.com.br

$\mathrm{Na}$ culinária, já é utilizada como aperitivo para substituir ou em associação à castanha do caju e castanha do Pará. Também já é utilizada para substituir o cacau e amendoim para a preparação de biscoitos (CAETANO et al., 
2017), e chocolates, barras de cereais, bolos, granolas e paçocas (SANTOS et al., 2012). Bebida fermentada saborizada com a amêndoa também já foi processada com boa aceitação, no intuito de substituir fermentação do leite pela de grãos produzindo probióticos em virtude da alta prevalência de intolerância a lactose (FIORAVANTE et al., 2017).

Devido ao baixo custo, o óleo vegetal mais consumido no Brasil é o de soja, porém há uma demanda por novos óleos com composição química diferente (SANTOS et al., 2012). Por conter altos valores de lipídios, a amêndoa do baru tem sido utilizada para obtenção de óleo comestível e os resíduos desta produção já foram avaliados para a produção de farinha de baru parcialmente desnatada para fins de panificação em substituição da farinha de trigo. Nesta farinha foram encontrados valores de cálcio $(200,91 \mathrm{mg} / 100 \mathrm{~g})$ próximos aos da farinha de soja (206 mg/100g) e maiores quando comparados aos valores de milho (34 mg/100g) e trigo (18 mg/100g) (PINELI et al., 2015).

\section{CONSIDERAÇÕES FINAIS}

Com uma alta biodiversidade o cerrado brasileiro e suas espécies frutíferas, como o $D$. alata, merecem maiores fontes de financiamento em pesquisas sobre para aprofundar o conhecimento sobre a caracterização botânica de suas espécies e suas interações ecológicas.

Mediante o exposto, observamos que o agroextrativismo reforça a ideia do cerrado "em pé", uso racional dos recursos desse bioma, onde já tenha sofrido intervenção, otimizando os efeitos das interações dos cultivos agrícolas e produção animal. Acreditamos ser possível a utilização da espécie $D$. alata pelos agricultores como renda complementar e até mesmo como renda principal, por meio da produção comercial.

Ressaltamos que estudos e divulgação sobre a caracterização botânica e investimentos em melhorias da cadeia produtiva da espécie podem contribuir para a conservação do bioma. Assim como a divulgação maciça destas informações contribuindo para a geração de conhecimento para a comunidade científica e os produtores rurais dando um suporte para a produção, consequentemente aumentando a renda dos produtos rurais destas regiões.

\section{REFERÊNCIAS}

ALBUQUERQUE, A. W.; SANTOS, J. R.; FILHO, G. M.; REIS, L. S. Plantas de cobertura e adubação nitrogenada na produção de milho em sistema de plantio direto. Revista Brasileira de Engenharia Agrícola e Ambiental, Campina Grande, v. 17,n. 7,p. 721-726, 2013. Disponível em: <http://www.agriambi.com.br/revista/v17 n07/v17n07a05.pdf.> Doi: http://dx.doi.org/10.1590/S1415-43662013000700005.

ALMEIDA, S. P.; PROENÇA, C. E. B.; SANO, S. M.; RIBEIRO, J. F. Cerrado: espécies vegetais úteis. Planaltina: EMBRAPA-CPAC, 1998. $464 \mathrm{p}$.

ANDRADE K. L.; ASSIS, R. Q.; SOUZA, E. C.; COTRIM, W. S.; RODRIGUES, L. J. Elaboração de panetone integral adicionado de amêndoa de baru (Dipteryx alata Vog.). Revista Brasileira de Produtos Agroindustriais, Campina Grande. 2016; v.18, n.1. http://www.deag.ufcg.edu.br/rbpa/rev181/rev1811.pdf 
ARAKAKI, A. H.; SCHEIDT, G. N.; PORTELLA, A. C.; ARRUDA, E. J.; COSTA, R. B. O baru (Dipteryx alata Vog.) como alternativa de sustentabilidade em área de fragmento florestal do Cerrado, no Mato Grosso do Sul. Interações, Campo Grande. 2009, v. 10, n. 1, p. 31-39. http://www.scielo.br/pdf/inter/v10n1/04.pdf

ARAUJO, W. O.; SANTOS, D. M.; ASCHEN, D. P. R. Otimização do processo de extração de açúcares redutores da polpa do baru. Agrotec, Revista Agrotecnologia, Anápolis. 2013; v.4, n.2.

BAILÃO, E.; DEVILLA, I.; DA CONCEIÇÃO, E.; BORGES, L. Bioactive Compounds Found in Brazilian Cerrado Fruits. Internatinal Journal of Molecular Sciences. 2015. Oct 9; v.16, n.10, p 231-283, 2015. https://doi.org/10.3390/ijms161023760

BRAKO, L.; ZARUCCHI, J. L. Catalogue of the flowering plants and gymnosperms of Peru. Monographs in Systematic Botany from the Missouri Botanical Garden, 45(4), 1-1286, 1993.

CAETANO, K. A.; CEOTTO, J. M.; RIBEIRO, A. P. B.; MORAIS, F. P. R.; FERRARI, R. A.; PACHECO, M. T. B.; CAPITANI, C. D. Effect of baru (Dipteryx alata Vog.) addition on the composition and nutritional quality of cookies. Food Science Technology, Campinas, 37(2): 239-245, Apr.-June 2017. http://dx.doi.org/10.1590/1678-457X.19616

CANUTO, D. S. O.; DARLIN, U. G. Z.; MORAES, M. A.; SILVA, A. M.; MORAES M. L. T.; FREIRAS, M. L. M. Caracterização genética de um teste de progênies de Dipteryx alata Vog. Proveniente de remanescente florestal da Estação Ecológica de Paulo de Faria, SP, Brasil. Hoehnea. 2015; 42(4): 641-648, 2 tab. http://dx.doi.org/10.1590/2236-8906-13/RAD/2015.

CARNEIRO, V. A.; GOMES H. B.; NASSER M. D.; RESENDE H. G. O baru (Dipteryx alata Vog.) como exemplo de renda e sustentabilidade de comunidades rurais no cerrado goiano: um relato de experiência via seminários da disciplina 'Sistemas Agrários de Produção e Desenvolvimento Sustentável". Revista Interatividade, Andradina, SP. 2014; v.2, n.2.

CORREA, G. D. C.; NAVES, R. V.; ROCHA, M. R. D.; ZICA L. F. Caracterização física de frutos de baru (Dipteryx alata Vog.) em três populações nos cerrados do estado de Goiás. Pesquisa Agropecuária Tropical, Goiânia: UFG. 2000; v.30, n.2, p.05-11

CORREA, G. C.; NAVES, R. V.; ROCHA, M. R.; CHAVES, L. J.; BORGES, J. D. Determinações físicas em frutos e sementes de baru (Dipteryx alata Vog.), cajuzinho (Anacardium othonianum Rizz.) e pequi (Caryocar brasiliense Camb.), visando melhoramento genético. Bioscience Journal, Uberlândia: UFU. 2008; v.24, n.4, p.42-47.

FERnANDES, D. C.; ALVES, A. M.; CASTRO, G. S. F.; JORDÃO, A. A. J. R.; NAVES, M. M. V. (2015). Effects of baru almond and Brazil nut against hyperlipidemia and oxidative stress in vivo. Journal of Food Research, 4(4), 38-46. http://dx.doi.org/10.5539/jfr.v4n4p38. 
FERRAZ, M. C.; YOSHIDA, E. H.; TAVARES, R. V.; COGO, J. C.; CINTRA, A. C.; DOS SANTOS, M. G.; RESENDE, F. A.; VARANDA, E. A.; HYSLOP, S.; PUEBLA, P.; SAN FELICIANO, A.; OSHIMA-FRANCO, Y. An isoflavone from Dipteryx alata Vogel is active against the in vitro neuromuscular paralysis of Bothrops jararacussu snake venom and bothropstoxin I, and prevents venom-induced myonecrosis. Molecules. May 6; v. 19, n.5, p.5790-805, 2014.

FERREIRA, R. A.; BOTELHO, A. S.; DAVIDE, A. C.; MALAVASI, M. M. Caracterização morfológica de fruto, semente, plântula e muda de Dipteryx alata Vog -Baru (Leguminosae Papilionoideae). Revista Cerne. 1998; v.4, n.1.p073-086.

FETZER, D. L.; CRUZ, P. N.; HAMERSKI, F.; CORAZZA, M. L. Extraction of baru (Dipteryx alata vogel) seed oil using compressed solvents Technology. The Journal of Supercritical Fluids. 137 (2018) 23-33

FIORAVANTE, M. B.; HIANE, P. A.; BRAGA, N. J. A. Elaboration, sensorial acceptance and characterization of fermented flavored drink based on water-soluble extract of baru almond. Ciência Rural, Santa Maria. 2017; v.47, n.9.https://dx.doi.org/10.1590/0103-8478cr20151646.

LEMOS, M. R. B.; SIQUEIRA, E. M. A.; ARRUDA, S. F.; ZAMBIAZI, R. C. The effect of roasting on the phenolic compounds and antioxidant potential of baru nuts (Dipteryx alata Vog.) Food Research International. 2012; 48, 592-597. doi:10.1016/j.foodres.2012.05.027.

MARCELINO, G.; COLETA, I. T.; CANDIDO, C. J.; SANTOS, E. F. Caracterização e análise sensorial de cupcakes elaborados com diferentes concentrações de farinha de casca e polpa de baru (Dipteryx alata Vog.) Multitemas, Campo Grande, MS, v. 23, n. 54, p. 265-281, maio/ago. 2018. DOI: $\mathrm{h} \square$ p://dx.doi.org/10.20435/mul $\square$ .$v 23 i 54.1753$

MENDONÇA, R. C.; FELFILI, J. M.; WALTER, B. M. T.; SILVA JÚNIOR, M. C.; REZENDE, A. V.; FILGUEIRAS, T. S.; NOGUEIRA, P. E. (1998). Flora vascular do Cerrado. In S. M. Sano, \& S. P. Almeida (Eds.), Cerrado: Ambiente e Flora (pp. 286-556). Brasil: Empresa Brasileira de Pesquisa Agropecuária do Brasil (EMBRAPA-CPAC). 2008

MORAES, C.; ANJOS, J. L. V.; MARUNO, M. ALONSO, A.; ROCHA-FILHO, P. Development of lamellar gel phase emulsion containing baru oil (Dipteryx alata Vog.) as a prospective delivery system for cutaneous application. Asian Journal of Pharmaceutical Sciences. Volume 13, Issue 2, March 2018, Pages 183-190

NABOUT, J. C.; SOARES, T. N.; DINIZ-FILHO, J. A. F.; DE MARCO, P.; TELLES, M. P. C.; NAVES, R. V.; CHAVES, L. J. Combining multiple models to predict the geographical distribution of the Baru tree (Dipteryx alata Vogel) in the Brazilian Cerrado. Brazilian Journal Biology. 2010; v.70, n.4, p.911-919. http://dx.doi.org/10.1590/S1519-69842010000500001. 
NIERI, E. M.; MACEDO, R. L. G.; MARTINS, T. G. V.; MELO, L. A.; VENTURIN, R. P.; VENTURIN, N. Comportamento silvicultural de espécies florestais em arranjo para integração pecuária floresta. Floresta, Curitiba, PR, v. 48, n. 2, p. 195-202, abr/jun. 2018. DOI: 10.5380/rf.v48 i2.54744

NUnes, Â. A.; FAVARO, S. P.; MiRANDA, C. H.; NEVES, V. A. Preparation and characterization of baru (Dipteryx alata $\mathrm{Vog}$ ) nut protein isolate and comparison of its physicochemical properties with commercial animal and plant protein isolates. Journal Science Food Agriculture. Mar 8 v. 17, p 30131-5, 2016

OLIVEIRA, M. I. B.; SIGRIST, M. R. Fenologia reprodutiva, polinização e reprodução de Dipteryx alata Vogel (Leguminosae-Papilionoideae) em Mato Grosso do Sul, Brasil. Revista Brasil Botânica. 2008; v.31, n.2, p.195-207.

PINELI, L. L. O; CARVALHO, M. V.; AGUIAR, L. A. A.; OlIVEIRA, G. T.; CELESTINO, S. M. C.; BOTELHO, R. B. A.; CHIARELLO, M. D. Use of baru (Brazilian almond) waste from physical extraction to produce flour and cookies.

$\begin{array}{llll}\text { Food Science } & \text { 50 } & & \end{array}$ http://dx.doi.org/10.1016/j.Iwt.2014.09.035

PINELI, L.; OLIVEIRA, G.; MENDONÇA, M.; BORGO, L.; FREIRE, E.; CELESTINO, S. CHIARELLO, BOTELLO R. Tracing chemical and sensory characteristics of baru oil during storage under nitrogen. LWT - Food Science and Technology. 2015b; v.62, 2. DOI: 10.1016/j.Iwt.2015.02.015.

PUTZEL, L; PETERS, C.M.; ROMO, M. Post-logging regeneration and recruitment of shihuahuaco (Dipteryx spp.) in Peruvian Amazonia: Implications for management. Ecology and Management, 261 (2011) 1099-1105

RESENDE, O; OLIVEIRA, D. E. C.; COSTA, L. M. FERREIRA JUNIOR, W. N. Cinética de secagem de frutos de baru (Dipteryx alata Vogel). Engenharia Agrícola. 2018, vol.38, n.1, pp.103-109.http://dx.doi.org/10.1590/1809-4430eng.agric.v38n1p103-109/2018

RIBEIRO, J. F.; SANO, S. M.; BRITO, M. A. Baru (Dipteryx alata Vog.). Jaboticabal: Funep. 2000. 41 p. 27

SANO, S. M.; BRITO, M. A.; RIBEIRO, J. F. Dipteryx alata (Baru). In: VIEIRA, R. F.; CAMILLO, J.; CORADIN, L. Espécies nativas da flora brasileira de valor econômico atual ou potencial: plantas para o futuro: Região Centro-Oeste. Brasília, DF: MMA, 2016. (Série Biodiversidade; 44).

SANTOS, G. G.; SILVA, M. R.; LACERDA, B. C. L.; MARTINS, D. M. O.; ALMEIDA, R. A. Aceitabilidade e qualidade físico-química de paçocas elaboradas com amêndoa de baru. Pesquisa Agropecuária Tropical. 2012; v.42, n.2.

SANTOS, P.; AGUIAR, A. C.; VIGANÓ, J.; BOIENG, J. V. V.; MARTÍNEZ, J. Supercritical $\mathrm{CO}_{2}$ extraction of cumbaru oil (Dipteryx alata Vogel) assisted by ultrasound: Global yield, kinetics and fatty acidcomposition. Journal of Supercritical Fluids, 107 (2016) 75-83. 
SAWYER, D. Dramas of the commons in Brazil. Sustentabilidade em Debate, Brasília. 2012; v. 3, n.2, p.257-274.

SILVA, L. A.; RESENDE, O.; VIRGOLINO, Z. Z.; BESSA, J. F. V.; MORAIS, W. A.; VIDAL, V. M. (2015) Cinética de secagem e difusividade efetiva em folhas de jenipapo (Genipa americana L.). Revista Brasileira de Plantas Medicinais 17(4):953-963.

SIQUEIRA, A. C. M. F.; NOGUEIRA, J. C. B.; KAGEYAMA, P. Y. Conservação dos recursos genéticos ex situ do Cumbaru (Dipteryx alata) Vog - Leguminosae. Revista do Instituto Florestal, 5(2), 231-243, 1993.

SIQUEIRA, A. P. S.; CASTRO, C. F. S.; SILVEIRA, E. V.; LOURENÇO, M. F. C. Chemical quality of Baru almond (Dipteryx alata). Ciência Rural, Santa Maria, v.46, n.10, p.1865-1867, out, 2016. http://dz.doi.org/10.1590/0103-8478cr20150468

SOARES, F. M. S. Conjuntura mensal Baru amêndoa. C In: Companhia Nacional de Abastecimento (Conab). Proposta de Preços Mínimos: safra 2014/2015 produtos da sociobiodiversidade. Brasília, Volume II, 2015.

SOUSA, A. G. O.; FERNANDES, D. C.; ALVES, A. M.; FREITAS, J. B.; NAVES, M. M. V. Nutritional quality and protein value of exotic almonds and nut from the Brazilian Savanna compared to peanut. Food Research International. 2011; 44, 827-834.

SOUZA, P. L.; SILVA, M. R. Quality of granola prepared with dried caju-do-cerrado (Anacardium othonianum Rizz) and baru almonds (Dipteryx alata Vog). Journal Food Science Technology. Mar; v. 52, n. 3, p 1712-7, 2015.

TARAZI, R.; MORENO, M. A.; GANDARA, F. B. High levels of genetic differentiation and selfing in the Brazilian cerrado fruit tree Dipteryx alata Vog. (Fabaceae). Genetics and Molecular Biology, 33(1), 78-85, 2010.

VALE, A. T.; OLSEN, L. B. Produção de carvão vegetal de casca de baru (Dipteryx alata) utilizando células de carbonização. Floresta, Curitiba, PR. 2013; v.43, n.1. 